\title{
Desenvolvimento Local Integrado e Sustentável: uma metodologia para políticas e programas de superação da pobreza
}

Integrated and Sustainable Local Development: a methodology for policies and programs designed to overcome poverty

Développement local intégré et durable: une méthodologie pour des politiques et des programmes de dépassement de la pauvreté

Desarrollo Local, Integrado y Sostenible: una metodología para las políticas y programas de superación de la pobreza

\section{Adriane Vieira Ferrarini*}

Recebido em 02/03/2012; revisado e aprovado em 03/05/2012; aceito em 30/03/2012

\begin{abstract}
Resumo: Ações dispersas e tuteladas ainda predominam nos programas de superação da pobreza. O desenvolvimento local integrado e sustentável, utilizado na política pública como fundamento e metodologia, oportunizou o fortalecimento da participação da população como cogestora, a articulação intersetorial de programas e a ativação de recursos endógenos do território, atribuindo caráter emancipatório e sustentabilidade aos resultados.

Palavras-chave: Pobreza. Política pública. Território.
\end{abstract}

Abstract: Dispersed and subordinate actions still predominate in programs designed to overcome poverty. The integrated and sustainable local development, used in public policy as its basis and methodology, promoted the strengthening of the people's participation as co-manager, the intersectoral articulation of programs and the activation of endogenous resources in the territory, giving an emancipatory and sustainable dimension to the results. Key words: Poverty. Public policy. Territory.

Résumé: Des actions dispersées et soumises à des tutelles prédominent dans les programmes de dépassement de la pauvreté. Le développement local intégré et durable, en tant que fondement et méthodologie en politique publique, a favorisé le renforcement de la participation de la population comme co-gestionnaire, l'articulation inter-sectorielle des programmes et l'activation des ressources endogènes du territoire, ce qui donne aux résultats un caractère émancipateur et de la durabilité.

Mots-clés: Pauvreté. Politique publique. Territoire.

Resumen: Acciones dispersas y subordinadas aún predominan en los programas para superar la pobreza. El desarrollo local integrado y sostenible, utilizado como la base y la metodología en las políticas públicas, hizo posible la participación de la población como co-gestora, la articulación intersectorial de los programas y la activación de los recursos endógenos del territorio, dando carácter de emancipación y sostenibilidad a los resultados.

Palabras clave: Pobreza. Políticas públicas. Território.

\section{Introdução}

O modo de desenvolvimento econômico globalizado, pautado no expansionimo produtivista ilimitado e propalado como caminho único para o progresso, priorizou a acumulação de capital e secundarizou as necessidades de reprodução das múltiplas formas de vida - humana e da natureza (SACHS, 2008; VEIGA, 2006; LEROY et al., 2002; ARRIGHI, 1997), gerando uma crise moral, social e cultural sem precedentes. $\mathrm{O}$ aumento da desigualdade e da pobreza e a utilização desordenada dos recursos naturais são expressões de uma mesma questão social e requerem intervenções conjuntas que considerem a interdependência entre a ação humana e a natureza (LATOUCHE, 2006; LIMA, 2002; SANTOS; SILVEIRA, 2001).

O Brasil, nos últimos anos, tem conseguido melhorar significativamente seus indicadores sociais. Porém dados recentes do Instituto de Pesquisa Estatística Aplicada (IPEA) (2001) afirmam que não são os programas governamentais voltados à proteção social e ao combate à pobreza que interferem

\footnotetext{
* Assistente Social, mestre em Serviço Social pela Pontifícia Universidade Católica do Rio Grande do Sul (PUCRS) e doutora em Sociologia pela Universidade Federal do Rio Grande do Sul (UFRGS), com doutorado sanduíche no Centro de Estudos Sociais (CES) da Universidade de Coimbra em Portugal. Professora e pesquisadora do Programa de Pós-graduação em Ciências Sociais da Universidade do Vale do Rio dos Sinos (UNISINOS), São Leopoldo, RS. Membro dos Grupos de Pesquisa em Economia Solidária e em Empreendedorismo e Inovação Social (UNISINOS). O artigo foi produzido a partir de pesquisa empírica de doutorado em Sociologia, realizado na Universidade Federal do Rio Grande do Sul sob a orientação do Prof. Dr. Antonio David Cattani, e de estudos teóricos posteriores. E-mail: adrianevf@unisinos.br
} 
substancialmente nos indicadores, mas o aumento do salário mínimo e das pensões. $\mathrm{O}$ crescimento econômico e o acesso ao consumo são importantes, contudo, insuficientes quando direitos de imensa parcela da população têm sido violados e a cidadania tem sido tutelada (JACCOUD, 2005; SILVA, 2001; LAVINAS et al., 2000).

Nesse sentido, a Constituição de 1988 inaugurou uma nova era também nas políticas públicas e sociais, atribuindo alicerces legais e fundamentos eticopolíticos no sentido da democratização das políticas e da expansão e universalização de direitos sociais (DRAIBE, 2002; SOUZA, 2006; YAZBEK, 2011). O Sistema Único de Assistência Social (SUAS) é expressão disso, assim como os programas Fome Zero e, recentemente, o Brasil sem Miséria. Inúmeras ações do poder público têm sido empreendidas (políticas cada vez mais descentralizadas, territorializadas e participativas), assim como da sociedade civil organizada. Contudo predominam ações dispersas e, em geral, limitadas em seu grau de abrangência e de impacto.

Neste texto, o objetivo é apresentar o desenvolvimento local integrado e sustentável como fundamento e metodologia para a implementação de programas e projetos que contribuam para a superação da fragmentação nas ações desenvolvidas em contextos de pobreza e ampliação da sustentabilidade nos resultados e impactos. Para tanto, serão trazidos de forma sucinta conceitos básicos para a compreensão da noção de superação sustentável da pobreza, desafios socioinstitucionais e tecnicopolíticos para a política pública e uma experiência prática em política para análise de seus limites, possibilidades e contribuição ao tema.

\section{Política emancipatória: concepções e desafios}

As duas últimas décadas têm sido marcadas pelo aumento das preocupações e esforços de combate à pobreza em âmbito global, em primeiro lugar, devido ao avanço da constituição formal de direitos humanos que tornaram inaceitável a manutenção da histórica falácia da culpabilização do pobre por sua condição de pobreza, geralmente apoiados em explicações individualizantes e psicologizantes (CATTANI; FERRARINI, 2010). É cada vez mais evidente, tanto a existência de direitos econômicos, quanto o não cumprimento destes, fato que, numa sociedade capitalista, gera a impossibilidade de exercício de outros direitos. As condições concretas de subsistência com relativa autonomia na sociedade capitalista contemporânea ficam fortemente adstritas à esfera do mercado.

O homem que emprega, governa na proporção do número de homens empregados. Ele possui poder, não de masmorra e forcas [...], mas de horas extraordinárias e de horário reduzido, de barrigas cheias e de barrigas vazias, de saúde e de doença. (HEILBRONER, 1988, p. 73).

Em segundo lugar, a questão ambiental adquire importância crescente, denunciando os limites do modelo de desenvolvimento hegemônico também na esfera social dada a indissociabilidade entre ambas as dimensões. As agressões ao ser humano e à natureza inscrevem-se na mesma lógica de priorização das necessidades do capital sobre a vida, sendo as populações pobres aquelas mais duramente afetadas pelos problemas ambientais. $\mathrm{O}$ meio ambiente passou a demandar atitudes e ações imediatas que, sem o acompanhamento do trabalho social, não se mostraram efetivas.

Apesar dos esforços e recursos empreendidos por governos, organismos internacionais e a sociedade civil organizada, a superação da pobreza, tanto em âmbito global quanto nacional, tem apresentado resultados insuficientes. $\mathrm{O}$ debate sobre as causas desse fenômeno é amplo e exigiria a análise de um conjunto de elementos políticos e econômicos que transcendem o escopo deste artigo. O foco aqui está posto na dimensão metodológica e técnica em programas nos quais os gestores supostamente apresentam vontade política no sentido da emancipação social e sustentabilidade dos resultados. Estudos e pesquisas demonstram que superar a pobreza de forma emancipatória e sustentável supõe a transcendência da dinâmica de compensação e de reação rumo à proatividade através do estímulo a processos de produção material e imaterial que permitam à população envolvida "andar com as próprias pernas" após o término do programa ou dos recursos alocados.

É corrente a definição de política emancipatória como política que se volta à perspectiva da oportunidade, e não da caridade. 
Oportunidades são representadas pela posse de ativos, tais como: educação, microcrédito e reforma agrária e pela forma como são apropriados. A posse de ativos desempenha três funções fundamentais no combate à pobreza: (i) promove utilidades e aumenta a capacidade de geração de renda; (ii) permite lidar melhor com choques adversos, pois funciona como reserva e potencial e (iii) reforça os recursos, tanto econômicos quanto humanos, sociais, culturais e políticos, do público envolvido (DEMO, 2003).

A ideia de política emancipatória também está ligada aos discursos de coconstrução (PESTOFF, 2011), de fazer "com" e não "para", de ser sujeito e não objeto, os quais não são novos, porém não é fácil fazêlos "sair do papel". A implementação de políticas emancipatórias depende, em primeiro lugar, da capacidade empreendedora e autogestionária de indivíduos, grupos e comunidades, competência que não emerge de forma voluntarista em segmentos populacionais marcados pela subsunção a relações políticas instituídas de cunho autoritário e paternalista. Em segundo lugar, ela requer a superação de características tradicionais arraigadas na política pública brasileira, tais como a fragmentação (tanto setorial quanto organizacional), programas top down, muitas vezes inadequados para a comunidade ou público-alvo, e a falta de articulação local com entidades da sociedade civil.

Perspectivas metodológicas de políticas emancipatórias supõem uma nova matriz de ordenamento e governança, mais flexível, que procura apreender as novas formas de organização e interseção do tecido social nas suas relações diversificadas com a gestão da democracia, fortalecimento da cidadania e enfrentamento da pobreza. A eficácia de tais princípios normativos e estratégias institucionais está condicionada pelas relações políticas locais e sua capacidade de organização, bem como pela forma como as forças econômicas do território têm encaminhado o processo de desenvolvimento local (IVO, 2001).

Em síntese, pode-se afirmar que o combate sustentável à pobreza passa a ser visto como a geração de processos de desenvolvimento, sendo os fundamentos e metodologia do desenvolvimento local, integrado e sustentável férteis para tal intento. A análise de conceitos básicos implicados na metodologia contribui para a compreensão dessa afirmação.

Conceitualmente, desenvolvimento significa ação proativa, identificação e ativação de recursos endógenos capazes de criar um processo virtuoso e instaurar ações autônomas; é, portanto, desencadeado de dentro para fora; é qualitativo e multidimensional. As dificuldades para o desenvolvimento de segmentos populacionais excluídos, ou ainda, incluídos de forma periférica evidenciam o engodo da sociedade de consumo como modelo de desenvolvimento global (SACHS, 2008; LEROY et al., 2002), o que cria um momento fértil para a emergência de alternativas epistemológicas e socialmente inovadoras. $\mathrm{O}$ desenvolvimento a ser fomentado pela política pública emancipatória poderia ser definido como contra-hegemônico, porque é produzido na chamada periferia, sob princípios de solidariedade e sustentabilidade, em bases territoriais e de forma democrática.

Contudo não basta propugnar a redefinição conceitual de formas de superação da pobreza sem referir-se a mudanças práticas. $\mathrm{Na}$ realidade, é radical tanto a perspectiva de desenvolvimento alternativo (mais próximo do que experiências inovadoras hoje conseguem atingir) quanto da alternativa ao desenvolvimento (que remete a outras epistemologias). Em qualquer perspectiva, o predomínio do capitalismo não reduz a amplitude das possibilidades; ao contrário, demanda revisões e aponta para formas de produção, intercâmbio e consumo não capitalistas. Frente ao seu caráter não sistêmico, essas experiências são frágeis e incipientes, o que não implica que se renuncie à análise rigorosa e à crítica numa perspectiva de "hermenêutica das emergências" que interpreta de maneira abrangente a resistência (SANTOS, 2002). A instauração de processos de desenvolvimento em escala local é viável e desejável - apesar de complexa - num horizonte de médio prazo, com adequado acompanhamento tecnicopolítico.

Outro conceito que merece reflexão neste texto é o "local", que diz respeito ao território, definido a partir das referências, potencialidades e necessidades que a comunidade enuncia. Apesar de constituir um paradigma que se relaciona com as ideias 
de desenvolvimento sustentável, inovação, governança local e soluções inovadoras partilhadas, a tendência de desconcentração e descentralização das ações públicas na direção dos contextos locais proporciona

[...] a formação de um consenso vago e instável porque partilhado por diferentes atores de registros político-ideológicos distintos, que vão desde as demandas de participação social nas decisões políticas, no controle social e democratização da política e da sociedade até os diagnósticos e recomendações apresentadas pelas diversas cúpulas internacionais. (IVO, 2001, p. 18).

As ações localizadas inserem-se num campo nublado e polissêmico porque podem afirmar valores que não resistem quando confrontados aos determinantes estruturais mais amplos, podendo inclusive reafirmar processos de hegemonia política, especialmente se considerados os contextos autoritários e o clientelismo paternalista que caracteriza a construção de identidades e sociabilidades locais no contexto brasileiro, revertendo os objetivos iniciais da ação e assumindo a forma de mitos regulatórios de uma sociedade fragmentada. Tais mitos podem reforçar o isolamento, a exclusão e a segregação ou ainda alimentar projetos identitários perversos (IVO, 2001).

Tais riscos requerem, por um lado, profundo debate das práticas de modo a contribuir para a instauração de uma vigilância epistemológica e eticopolítica na análise das experiências locais e evitar afirmações idealizadoras e salvacionistas (FERRARINI, 2008). Por outro lado, se percebe a necessidade de olhar para as ações locais a partir delas mesmas, revertendo-se a tendência de se conceber a dimensão local através de parâmetros de uma monocultura da escala dominante, segundo a qual os países desenvolvidos, empresas e universidades se impõem sobre as comunidades de modo inexorável, pois possuem recursos financeiros, conhecimento e poder. Nessa lógica, a comunidade evoluirá tanto quanto for sua capacidade de se adaptar aos critérios de consumo, estéticos e culturais dominantes (SANTOS, 2003).

A desconstrução epistemológica da perspectiva positivista de conceber as escalas permite perceber - sem negar as determinações globais - que o local não se encontra absoluta e totalmente subjugado; não é mero produto ou resultado do global, como folha em branco sobre a qual se imprimem modos de produzir e de viver. O local sofre determinações, mas é também o espaço da possibilidade de criações inusitadas e soluções não contidas na totalidade. Santos (2003) propõe pensar os termos das dicotomias fora das articulações e relações de poder que os unem para revelar outras relações alternativas que têm sido ofuscadas pelas dicotomias hegemônicas. "Pensar o Sul como se não houvesse o Norte, pensar a mulher como se não houvesse o homem, pensar o escravo como se não houvesse o senhor" (SANTOS, 2003, p. 743). Na questão das escalas, pensar o local como se não houvesse o global para que o olhar afirmativo e de dentro para fora permita a emergência de experiências singulares.

Localização é o conjunto de iniciativas que visam criar ou manter espaços de sociabilidade de pequena escala, comunitários, assentes em relações face a face, orientados para autossustentabilidade e regidos por lógicas cooperativas e participativas. Não implica necessariamente fechamento isolacionista, mas medidas de proteção contra investidas predadoras da globalização e a favor do fortalecimento de sociabilidades locais (SANTOS, 2001). Desglobalizar o local permite o globalismo localizado, ou seja, a integração ou globalização de conhecimentos, tecnologias ou metodologias criadas em âmbito local.

O processo de implementação de políticas emancipatórias gera desafios socioinstitucionais e tecnicopolíticos. O primeiro desafio refere-se à intersetorialidade, necessária desde o momento do planejamento, visto as demandas serem multidimensionais, mas os programas e recursos encontrarem-se dispersos nas diferentes políticas públicas. A intersetorialidade supõe a articulação, tanto vertical (na esfera pública entre entes federativos) quanto horizontal (entre programas setoriais desenvolvidos no território e destes com as organizações sociais). Ela é necessária para a superação do paralelismo de ações que se tornam descontinuadas e ineficientes nos territórios, otimizando recursos e articulando as variadas iniciativas na busca de resultados multidimensionais.

Em termos socioinstitucionais, torna-se necessária a união entre os ministérios envolvidos para planejamento integrado, trans- 
cendendo a estrutura lógica dos orçamentos setoriais, rubricas, públicos-alvos específicos e metas. Em termos tecnicopolíticos, é importante que gestores e técnicos, atuando de forma conjunta, não recorram à mera sobreposição de diagnósticos e proposições, mas voltem-se à construção de um objeto comum a serviço das comunidades. Para ser efetiva, a intersetorialidade não depende apenas de um novo arranjo institucional (o que já significa um grande passo); ela exige uma mudança de paradigma. Por melhor que seja o planejamento, é no cotidiano da atuação dos técnicos e da população que a política ganha vida, demandando uma formação de agentes com habilidades comunicacionais e relacionais para promover relações e contextos acolhedores e democráticos, mediar conflitos e disputas (inerentes aos processos participativos), rever procedimentos técnicos e validar saberes práticos e populares.

O segundo desafio é a participação radicalizada e direta da comunidade como cogestora dos programas desenvolvidos no território, indo além dos avanços materiais e ativando o exercício da cidadania. A experiência apresentada a seguir pode inspirar respostas para os desafios elencados através do uso do método do desenvolvimento local integrado e sustentável na política pública.

\section{Uma experiência de política pública participativa e territorializada}

O Programa de Recuperação de Áreas Degradadas (PIRAD) foi desenvolvido no período de 1999 a 2002, sob a coordenação da METROPLAN (Fundação Estadual de Planejamento Metropolitano e Regional do Rio Grande do Sul), e executado por meio de parceria com a GTZ (Sociedade de Cooperação Alemã) e com a REFAP (Refinaria Alberto Pasqualini - Petrobrás). O PIRAD, programa vinculado à política de planejamento urbano estadual, tinha o objetivo inicial de recuperar urbana e ambientalmente áreas degradadas, mas permitiu a promoção de processos considerados sustentáveis na superação da pobreza através de sua concepção integrada, participativa e territorializada. O Programa teve a duração de um governo (entre os anos 1999 e 2002), mas mantém-se emblemático e atual em função das inovações propostas, além de ter sido retomado no ano de 2011 pela gestão pública estadual do RS, o que permitirá a continuidade dos estudos a seu respeito.

A pesquisa foi desenvolvida ao longo de quatro anos, de 2003 a 2006. Inicialmente, a coleta de dados foi realizada através de pesquisa documental na METROPLAN, organização regional responsável pela execução do PIRAD. Os técnicos disponibilizaram relatórios a partir dos quais foi possível fazer um levantamento acerca da história, concepções norteadoras, implementação e avaliação do Programa. Posteriormente, foram realizadas entrevistas semiestruturadas com oito gestores das três organizações envolvidas. Três gestores eram funcionários públicos ligados à METROPLAN, e cinco foram contratados como agentes locais da GTZ devido à sua qualificação técnica e experiências anteriores em processos participativos. Por último, foi realizado um estudo de caso no bairro Guajuviras, situado no município de Canoas, região metropolitana de Porto Alegre.

A experiência pesquisada não será apresentada na íntegra; serão retratados os princípios e metodologias que podem ser replicados, bem como os avanços e dificuldades encontrados no percurso da implementação. O PIRAD foi herdeiro do acúmulo de 18 anos de implementação do Programa de Viabilização de Espaços Econômicos para Populações de Baixa Renda (PRORENDA) e pautado na concepção e no emprego de metodologias participativas, que já vinham sendo aprimoradas desde então. A principal aprendizagem do PRORENDA foi a constatação acerca do enfraquecimento da participação popular à época, o que levou os técnicos do PIRAD a investir na formação técnica e política de grupos e no estímulo à construção de propostas coletivas, ao invés de focar nas ações e nos indivíduos.

Outras aprendizagens herdadas do PRORENDA foram, em primeiro lugar, a redefinição da noção de pobreza como fenômeno multidimensional, que não conhece limites administrativos. Com isso, o enfoque da política foi sendo modificado, passando da visão setorial predominante no início dos anos de 1990 para a concepção atual de desenvolvimento local. É na comunidade e no município que as relações sociais políticas e econômicas ampliam ou limitam o campo de escolhas da 
família. Na perspectiva do desenvolvimento local, o combate à pobreza passa a ser objetivo integrado, firmemente interconectado com os diversos outros elementos da qualidade de vida em cinco dimensões: inclusão social, fortalecimento da economia local, inovação na gestão pública, gestão e uso racional de recursos naturais e mobilização social.

A segunda redefinição consistiu na compreensão do projeto como instrumento temporário de teste e de consolidação de novos procedimentos, para o qual são alocados recursos humanos, materiais e financeiros não rotineiros (BARTH; BROSE, 2002). Não basta repassar recursos sem mobilizar, é necessário que a população queira e se organize para usá-los de forma efetiva. Bens e serviços são vistos como pretextos pedagógicos para a ativação da participação

Com base nisso, o PIRAD foi concebido a partir de dois eixos norteadores. O primeiro eixo priorizava a participação popular, pela qual os grupos envolvidos deveriam passar de objeto da política pública para sujeito. As ações desenvolvidas nas comunidades seriam pautadas pelo fortalecimento da sua capacidade de autogestão, valorizando os conselhos ou fóruns comunitários e municipais como instâncias de participação ativa da população, bem como reconhecendo a necessidade de viabilizar a formação de parcerias entre setor público e terceiro setor. O segundo eixo buscava a complementaridade das ações sociais com o enfoque produtivo através de atividades autogestionárias de trabalho e renda, as quais possibilitassem uma melhoria sustentável das condições de vida das famílias envolvidas.

A principal característica do PIRAD foi a utilização de metodologias participativas para fomentar a participação efetiva da população desde o planejamento das ações a serem desenvolvidas em determinada comunidade e não apenas na execução. Porém, o PIRAD sofreu resistências e descrença no início de sua implantação, tanto da METROPLAN, quanto dos parceiros: Petrobrás, Companhia Riograndense de Saneamento (CORSAN), Departamento Municipal de Água e Esgoto (DMAE) e Serviço Social do Comércio (SESC). A resistência era atribuída à introdução de novas metodologias e ampliação de ações e de sujeitos envolvidos.
O Programa também sofreu resistência interna por parte de agentes que já tinham um perfil de trabalho técnico consolidado nesse campo. A contratação de profissional para elaborar um diagnóstico é muito mais fácil, rápida e geralmente menos onerosa, porém ninguém tira o saber que a população adquire a partir do momento em que ela se reúne para identificar, analisar e compreender suas próprias demandas.

A execução ocorreu através de planejamento técnico inicial, aberto a alterações que adviriam das comunidades. A ideia era apresentar o projeto às comunidades dos municípios envolvidos (dez, em torno das três sub-bacias), contatar com lideranças, oferecer formação, formar núcleos comunitários que seriam cogestores no diagnóstico, planejamento, execução e monitoramento das ações locais.

Em paralelo, foram constituídos fóruns regionais, no total de três, um para cada sub-bacia em conjunto com as prefeituras, organizações nãogovernamentais e outras organizações que desejassem participar ou cuja participação fosse relevante. A articulação com as organizações públicas, privadas e sociedade civil ocorreu de acordo com a realidade de cada região e município. O Fórum Regional, de caráter deliberativo, era o espaço de debate, integração, articulação e cooperação da sociedade civil organizada com as diferentes instâncias da administração pública, tendo como objetivo o desenvolvimento da bacia hidrográfica (METROPLAN, 2002). Já os fóruns metropolitanos eram paralelamente o espaço de articulação e deliberação das demandas em âmbito regional com as organizações públicas, do terceiro setor e privadas; eles permitiam o planejamento das ações para além das comunidades, na perspectiva do desenvolvimento regional, bem como facilitavam a busca de recursos para os projetos elencados coletivamente.

A ação na comunidade e a articulação com múltiplas organizações envolvidas são dois elementos fundamentais para a análise do Programa. Na prática aconteceram de forma simultânea. Apesar de haver recursos e intenção dos agentes em desenvolver o trabalho, as comunidades aderiam de forma voluntária. As lideranças formavam o Núcleo Comunitário de Desenvolvimento que, 
inicialmente, se reunia de maneira informal para posteriormente assumir identidade jurídica própria e desempenhar crescente autonomia de ação no Programa; era uma forma de oportunizar e fortalecer o processo de cogestão da política.

O começo do trabalho pelas lideranças permitiu aproveitar a riqueza social existente na comunidade; tratou-se de considerar a história e fortalecer o que já existia. Os moradores participavam do desenvolvimento do Programa constituído de três etapas. A primeira visava à formação de lideranças. Começar o trabalho através das lideranças permitia o aproveitamento da riqueza social existente na comunidade; tratava-se de considerar a história e fortalecer o que já existia.

As pessoas que tinham atividades dentro do Núcleo convidavam outros moradores com potencial para o trabalho comunitário, com vistas a aflorar a liderança que cada um tem dentro de si (gestor 6).

O curso de capacitação de lideranças promovia a reflexão de seu papel na comunidade para o aprofundamento de trabalho em grupo e desenvolvimento de alguma atividade econômica. O conteúdo do curso foi alterado no sentido de: (1) focar no coletivo para evitar a formação de um indivíduo que se sobressairia dos demais e para contribuir com a redução de guetos; (2) questionar a forma simplista e não sustentável de geração de renda presente em muitos programas.

Acho que os agentes daquela época nos ajudaram a pensar, nos ajudaram a criar uma metodologia que pudesse ser de alcance de todos, que fosse trabalhar para a comunidade, aquela visão de comunidade, não aquela visão individualista. Ainda tem um pouco, mas a gente conseguiu tentar aquela consciência solidária (moradora 1).

A didática também foi aperfeiçoada através da adoção de dinâmicas intercaladas com reflexões e técnicas de visualização capazes de manter a atenção de moradores, cansados após a jornada de trabalho. $\mathrm{O}$ acompanhamento às lideranças no processo de capacitação e formação dos Núcleos era realizado através de reuniões semanais.

A segunda etapa foi a formalização do Núcleo e o diagnóstico das comunidades através do Diagnóstico Rápido Urbano Econômico Participativo (DRUEP), composto por várias técnicas. Uma delas era o "mapa falante", um conjunto de fotografias de áreas degradadas do bairro e de situações consideradas problemáticas, as quais necessitavam de intervenção. Outra técnica consistia em entrevistas com uma amostra de moradores do bairro através de visitas domiciliares a partir de pré-roteiro com perguntas abertas e fechadas. Após o trabalho de campo, as pessoas voltavam para o "QG" (em alusão a "quartel general"), elaboravam o diagnóstico preliminar em parceria com os técnicos e davam o primeiro retorno para os moradores entrevistados, que já haviam sido comunicados e convidados a participar. Essa estratégia tinha por objetivo evitar que instituições utilizassem a comunidade como objeto de conhecimento, sem que ela se percebesse como sujeito desse saber.

Aprendizado importante relatado pelos moradores que aplicaram o DRUEP refere-se ao fato de terem conhecido os verdadeiros problemas que havia na "periferia da periferia". Eles referiram que costumavam julgar certas famílias por sua apatia política, mas ao verem suas condições precárias de vida, passaram a solidarizar-se. Como resultado, deixaram de lado a atitude individualista de definir prioridades de acordo com interesses pessoais, buscando contemplar as necessidades prementes da comunidade como um todo.

Ao longo da pesquisa, foi possível constatar a preocupação com o estímulo permanente à corresponsabilidade nas ações. Não se tratava tão somente de se chegar aos resultados esperados, mas também de gerar processos de protagonismo, consciência de direitos e exercício de cidadania através das ações. "Nós não fazemos nada por ninguém. Fazer e dar pronto não é valorizado. Se a prefeitura vem com um caminhão para limpar a área, chamamos todos para fazer um mutirão e ajudar e depois todos vão ajudar a manter limpo" (gestor 1).

Após o diagnóstico, as prioridades eram definidas e sistematizadas no Plano de Desenvolvimento Local Integrado (PDLI), o qual apontava as demandas, tanto por melhorias físicas quanto sociais. Posteriormente, as demandas eram encaminhadas às respectivas secretarias e órgãos de execução. Os representantes das entidades executoras, que já estavam articulados com o PIRAD, viam a 
possibilidade de priorizar as necessidades do PDLI dentro dos recursos disponíveis, definiam o que podia ser feito e davam resposta rápida à comunidade.

A terceira etapa era a organização comunitária para a busca de recursos no orçamento participativo com vistas à ampliação das melhorias feitas e à execução de demandas reprimidas ou de propostas inovadoras, sendo a disputa por projeto a maior dificuldade. A geração de renda foi prioritária na maioria das comunidades, tendo sido atendida através do desenvolvimento de ações no campo da economia solidária, tais como: capacitação e de constituição de empreendimentos associativos, implantação do primeiro clube de trocas com moeda social do RS, criação do galpão de reciclagem e fortalecimento de redes locais de produção e consumo. A segunda demanda girou em torno da questão ambiental, a que mais agradava as instituições parceiras.

Os princípios e estratégias metodológicas foram igualmente aplicados em cada uma das sub-bacias em que o PIRAD foi desenvolvido.

A aceitação desse processo pela população local foi positiva e resultou na alocação de mais de três milhões de reais através do orçamento participativo de 2002 para a implementação de melhorias urbanas e de apoio para atividades de geração de trabalho e renda. (BARTH; BROSE, 2002, p. 70).

Ao todo foram capacitadas 570 lideranças através de centenas de cursos, oficinas e atividades ligadas aos processos da gestão participativa do Programa. Indiretamente, cerca de 400 mil habitantes foram beneficiados através de obras de infraestrutura e de programas educativos, de geração de renda realizados em parceria com programas da área do trabalho, cooperativismo e economia solidária. Além disso, foram formados 15 núcleos comunitários e um Fórum Regional de Desenvolvimento composto por ampla diversidade de atores, representantes de organizações comunitárias, dos poderes públicos municipal, estadual e federal, setor privado, instituições de ensino e organizações não governamentais.

\section{Considerações finais}

A recente melhoria dos indicadores econômicos e sociais do Brasil é meritória e necessária, mas insuficiente. Não se construirá a nação desenvolvida desejada sem que os avanços atuais venham acompanhados da participação cidadã, autossustentação econômica dos segmentos populacionais em situação de pobreza e uso racional dos recursos naturais. Nessa perspectiva, a superação da pobreza passa a ser uma questão de instauração de processos endógenos, inclusivos e autônomos de desenvolvimento.

A utilização de procedimentos e estratégias do desenvolvimento local integrado e sustentável mostrou-se válida para desencadear ações emancipatórias através da política pública brasileira. $\mathrm{O}$ destaque à dimensão metodológica na análise da experiência não foi casual; mesmo havendo intencionalidade política e social, os arranjos institucionais e operacionais são herdeiros de modelos fragmentados, verticalizados e assistencialistas, dificultando, na prática, a necessária assunção da intersetorialidade, participação popular, concertação entre atores sociais e territorialização.

Através da experiência pesquisada, o artigo apresentou uma metodologia que longe de ser tratada como modelo único ou receita - pode vir a ser replicada por diferentes políticas e programas sociais, particularizando-se em cada contexto a partir das características do território e da ação da população envolvida. A participação foi elemento central para o empoderamento sociopolítico da população envolvida; não se trata de consultar a população, mas dar-lhe ferramentas para enunciar de forma coletiva suas necessidades, prioridades e soluções - o que não significa prescindir do saber técnico, mas tê-lo a seu serviço, desconstruindo a tradicional hierarquia pautada no exclusivismo epistemológico do conhecimento científico e especializado, bem como a hierarquia estanque entre global e local. Outros elementos que se mostraram importantes para o êxito da ação foram: a qualificação de recursos humanos ou formação de agentes de desenvolvimento com habilidades comunicacionais e relacionais; a possibilidade de trabalhar a dimensão ambiental em estreita articulação com a social e o foco no território, 
que possibilitou a produção de ativos locais e atribuiu sustentabilidade aos resultados.

Contudo, ainda que políticas emancipatórias sejam ampliadas e que uma nova etapa de desenvolvimento nacional com maior justiça distributiva possa ser pensada, não se espera que a superação da pobreza seja processo de curto prazo devido ao enorme contingente de pobres, à gênese estrutural da pobreza, bem como suas características de intergeracionalidade e de multidimensionalidade. Além disso, processos participativos - imprescindíveis à emancipação social - não são simples nem imediatos; ao contrário, costumam ser complexos e demorados, motivo para eventuais momentos de descrença e desânimo de técnicos e da população envolvida. Porém, são mais efetivos e podem gerar experiências significativas e organizações fortes e contra-hegemônicas na direção de uma sociedade mais justa e solidária.

\section{Referências}

ARRIGHI, Giovani. A ilusão do desenvolvimento. Petrópolis: Vozes, 1997.

BARTH, Jutta; BROSE, Markus. Participação e desenvolvimento local: balanço de uma década de cooperação alemã no Rio Grande do Sul. Porto Alegre: Sulina, 2002.

CATTANI, Antonio D.; FERRARINI, Adriane V. Participação, desenvolvimento local e política pública: estratégias articuladas para a superação da pobreza. Revista Katálysis, Florianópolis, 13(2): 164-172, jul./ dez. 2010.

DEMO, Pedro. Pobreza da pobreza. Rio de Janeiro: Vozes, 2003.

DRAIBE, Sônia. BRASIL 1980-2000: proteção e insegurança sociais em tempos difíceis. Material preparado PNUD - Taller Inter-regional, Chile, 2002.

GOVERNO FEDERAL. Ministério do Planejamento, Orçamento e Gestão. Comunicados do IPEA n. 111. Mudanças recentes na pobreza brasileira, IPEA, 2011. Disponível em: http://www.ipea.gov.br/agencia/ images/stories/PDFs/comunicado/110915_comunicadoipea111.pdf. Acesso em: 15/9/2011 .

HEILBRONER, Robert. A natureza e a lógica do capitalismo. São Paulo: Ática, 1988.

IVO, Anete B. L. Metamorfoses da questão democrática: governabilidade e pobreza. Buenos Aires: CLACSO, 2001.
JACCOUD, Luciana. Questão social e políticas sociais no Brasil contemporâneo. Brasília: IPEA, 2005

LATOUCHE, Serge. O decrescimento como condição de uma sociedade convivial. Cadernos IHU Ideias, ano 4 (56), 2006.

LAVINAS, Lena et al. Combinando compensatório e redistributivo: o desafio das políticas sociais no Brasil. Rio de Janeiro: IPEA, 2000.

LEROY, Jean-Pierre et al. Tudo agora ao mesmo tempo: desenvolvimento, democracia, sustentabilidade: o que isso tem a ver com você? Rio de Janeiro: Vozes, 2002.

LIMA, Gustavo F. Crise ambiental, educação e cidadania: os desafios da sustentabilidade emancipatória. In: LOUREIRO, F.; LAYARGUES, P.; CASTRO, R. (Orgs.). Educação ambiental: repensando o espaço da cidadania. São Paulo: Cortez, 2002.

METROPLAN, Relatório de Gestão do Programa de Recuperação de Áreas Degradadas do RS, 2002.

PESTOFF, Victor. Co-Production, New Public Governance and Third Sector Social Services in Europe. Revista Ciências Sociais Unisinos, 47(1), p. 15-24, 2011.

SACHS, Ignacy. Desenvolvimento includente, sustentável, sustentado. Rio de Janeiro: Garamond, 2008.

SANTOS, Boaventura de Sousa. Conhecimento prudente para uma vida decente: 'um discurso sobre as ciências' revisitado. Lisboa: Afrontamento, 2003.

(Org.). Produzir para viver: os caminhos da produção não capitalista. Rio de Janeiro: Civilização Brasileira, 2002.

(Org.). Globalização: fatalidade ou utopia. Lisboa: Afrontamento, 2001.

. A crítica da razão indolente - contra o desperdício da experiência. Para um novo senso comum: a ciência, o direito e a política na transição paradigmática. São Paulo: Cortez, 2000. v. 1.

SANTOS, Milton; SILVEIRA, Maria Lúcia. Brasil: territorialidade e sociedade no início do século XXI. Rio de Janeiro: Record, 2001.

SILVA, Maria Ozanira (Coord.). O Comunidade Solidária: o não-enfrentamento da pobreza no Brasil. São Paulo: Cortez, 2001.

SOUZA, Celina. Políticas públicas: uma revisão da literatura. Sociologias, Porto Alegre, 8 (16), p. 20-45, jul/ dez, 2006.

VEIGA, José Eli. Desenvolvimento sustentável: o desafio do século XXI. Rio de Janeiro: Garamond, 2006.

YAZBEK, Maria C. Classes subalternas e assistência social. São Paulo: Cortez, 2011. 